УДК 82.091

DOI https://doi.org/10.26661/2414-9594-2021-1-34

\title{
СОПОСТАВИТЕЛЬНОЕ ИССЛЕДОВАНИЕ ТВОРЧЕСТВА Н.В. ГОГОЛЯ И ЛУ СИНЯ В КИТАЙСКОМ ЛИТЕРАТУРОВЕДЕНИИ: ПРОБЛЕМЫ ПЕРИОДИЗАЦИИ
}

\author{
Ли Хайин \\ аспирант \\ Институт филологии \\ Киевского национального университета имени Тараса Шевченко \\ бульв. Тараса Шевченка, 14, Киев, Украина \\ orcid.org/0000-0002-4553-3391 \\ lizi317323@gmail.com
}

Ключевые слова:

сопоставительный анализ, Лу Синь, Н.В. Гоголь, револючиионная парадигма, литературная парадигма.
В статье осуществляется сопоставительный анализ исследований, посвященных творчеству Лу Синя и Н.В. Гоголя в китайском литературоведении, систематизируются подходы к проведению подобного анализа, практиковавшиеся в разные периоды, обосновывается необходимость изучения различных парадигм, определявших направления сравнительных исследований в Китае, поскольку это поможет понять историю развития литературной критики в этой стране. Лу Синь и Н.В. Гоголь - два великих мастера литературы, сопоставительный анализ их произведений является классической темой не только в Китае, но и во всем мире. Традиционные сравнительные исследования их произведений часто были сосредоточены на таких аспектах, как влияние творчества Н.В. Гоголя на произведения Лу Синя, отличия в используемых литературных приемах, специфика образов человека, художественная идея произведений, цель творчества и т.д; при этом недостаточно внимания уделялось осмыслению подходов к исследованию творчества обоих писателей, соответственно, данная тема остается одной из наиболее актуальных в рамках сравнительного анализа творчества этих писателей. В Китае данная тема изучалась в работах таких исследователей, как Линь Вэйна (林炜娜), Гао Юй (高玉), Хуан Фаю (黄发有).

Цель данной работы заключается в изучении 70-ти летней истории сопоставительного анализа творчества Н.В. Гоголя и Лу Синя в контексте развития китайской литературы и литературоведения.

В процессе исследования было установлено, что историю сопоставительного анализа творчества Лу Синя и Гоголя в Китае в течение 70 лет можно разделить на 3 этапа: 1) 20-40 годы XX века: знакомство с творчеством Н. Гоголя в Китае, его распространение и первоначальное изучение; 2) 50-70 годы ХХ века: появление революционной парадигмы; 3) после 80-х годов XX века: формирование литературной парадигмы. Изучение работ китайских исследователей позволило установить, что с развитием литературной теории в Китае сравнительный анализ творчества Лу Синя и Гоголя осуществлялся на основании разных подходов, и парадигма исследования изменялась от революционной к литературной. 


\title{
ЗІСТАВНЕ ДОСЛІДЖЕННЯ ТВОРЧОСТІ М.В. ГОГОЛЯ ТА ЛУ СІНЯ В КИТАЙСЬКОМУ ЛІТЕРАТУРОЗНАВСТВІ: ПРОБЛЕМИ ПЕРІОДИЗАЦІЇ
}

\author{
Лі Хайїн \\ аспірант \\ Інститут філології \\ Київського національного університету імені Тараса Шевченка \\ бульв. Тараса Шевченка, 14, Київ, Україна \\ orcid.org/0000-0002-4553-3391 \\ lizi317323@gmail.com
}

Ключові слова: порівняльний аналіз, Лу Сінь, М.В. Гоголь, революичійна парадигма, літературна парадигма.
У статті здійснюється порівняльний аналіз досліджень, присвячених творчості Лу Сіня та М.В. Гоголя у китайському літературознавстві, систематизуються підходи до проведення подібного аналізу, що практикувалися в різні періоди, обгрунтовується необхідність вивчення різних парадигм, які визначали напрямки порівняльних досліджень в Китаї, оскільки це допоможе зрозуміти історію розвитку літературної критики в цій країні. Лу Сінь і М. В. Гоголь - два великих майстри літератури, порівняльний аналіз їхньої творчості є класичною темою не тільки в Китаї, але й у всьому світі. Традиційні порівняльні дослідження їхніх творів часто були зосереджені на таких аспектах, як вплив творчості М.В. Гоголя на твори Лу Сіня, відмінності в літературних прийомах, що використовуються, специфіка образів людини, художня ідея творів, мета творчості тощо, при цьому недостатньо уваги приділяється осмисленню підходів до дослідження творчості обох письменників, відповідно, ця тема залишається однією з найбільш актуальних у межах порівняльного аналізу творчості цих письменників. У Китаї цю тему вивчали Лінь Вейна (林炜娜), Гао Юй (高玉), Хуан Фаю (黄发有).

Мета пропонованої розвідки полягає в дослідженні 70-тирічної історії зіставного дослідження творчості М.В. Гоголя та Лу Сіня в контексті розвитку китайської літератури та літературознавства.

У процесі дослідження було встановлено, що історію порівняльного аналізу творчості Лу Сіня і Гоголя в Китаї протягом 70 років можна розділити на 3 етапи: 1) 20-40 роки ХХ століття: знайомство 3 творчістю М. Гоголя в Китаї, його поширення і початкове вивчення; 2) 50-70 роки XX століття: поява революційної парадигми; 3) після 80-х років XX століття: формування літературної парадигми.

Вивчення робіт китайських дослідників дозволило встановити, що 3 розвитком літературної теорії в Китаї, порівняльний аналіз творчості Лу Сіня і Гоголя здійснювався на підставі різних підходів, і парадигма дослідження змінювалася від революційної до літературної. 


\title{
COMPARATIVE ANALYSIS OF THE WORKS OF N.V. GOGOL AND LU XIN IN CHINESE LITERATURE: PROBLEMS OF PERIODIZATION
}

\author{
Li Haiying \\ Postgraduate Student \\ Institute of Philology \\ of Taras Shevchenko National University of Kyiv \\ Tarasa Shevchenko blvd, 14, Kyiv, 01601 \\ orcid.org/0000-0002-4553-3391 \\ lizi317323@gmail.com
}

Key words: comparative analysis, Lu Xun, N.V. Gogol, revolutionary paradigm, literary paradigm.
The article provides a comparative analysis of studies devoted to the work of $\mathrm{Lu}$ Xun and N.V. Gogol in Chinese literary criticism, systematizes the approaches to conducting such an analysis that were practiced in different periods, substantiates the need to study various paradigms that determined the directions of comparative research in China, as this will help to understand the history of the development of literary criticism in this country. Lu Xun and N.V. Gogol are two great masters in literary circles, comparative analysis of their works is a classic and endless topic not only in China, but throughout the world. Traditional comparative studies of their works are often focused on such aspects as the influence of N.V. Gogol on Lu Xun, differences in literary techniques, the specificity of characters, artistic ideas, the purpose of creativity, etc. Not enough attention is paid to comprehending the approaches to the study of the works of both writers, therefore this topic remains one of the most relevant in the framework of a comparative analysis of their works. In China, this topic was studied by Lin Weina (林炜娜), Gao Yu (高玉), Huang Fayou (黄发有).

The purpose of this work is to study the 70-year history of the comparative analysis of the works of N. V. Gogol and $\mathrm{Lu}$ Xun in the context of the development of Chinese literature and literary criticism.

During the research, it was found that the history of the comparative analysis of the works of $\mathrm{Lu}$ Xun and Gogol in China for 70 years can be divided into 3 stages: 1) 1920s-1940s: acquaintance with the work of N. Gogol in China, its spread and initial study; 2) 1950s-1970s: the emergence of the revolutionary paradigm; 3) after the 1980s: the formation of the literary paradigm.

The study of the works of Chinese researchers made it possible to establish that with the development of literary theory in China, a comparative analysis of the works of Lu Xun and Gogol was carried out on the basis of different approaches, and the research paradigm changed from revolutionary to literary.
Постановка проблемы. Сопоставительное исследование творчества Лу Синя и Н.В. Гоголя, двух великих мастеров литературы, до сих пор вызывает интерес китайских и зарубежных ученых-литературоведов. Исследуя работы, посвященные сопоставительному анализу творчества Гоголя и Лу Синя, можно утверждать, что данная тема уже длительный период актуальна в литературных исследовательских кругах Китая, более того, изучение данной темы велось с точки зрения различных подходов и теорий. Выбор сопоставительного анализа творчества Лу Синя и Н.В. Гоголя как объекта исследования обусловлен, прежде всего, наличием большого объема материалов по данной проблематике. По данным China
National Knowledge Infrastructure ${ }^{l}$, количество научных работ (статьи и диссертации), посвященных творчеству Н.В. Гоголя, с 1946 г. по 2021 г., составило 1610. Из них работ о сопоставлении творчества Лу Синя и Гоголя за указанный 70-летний период достигло 306. Основные аспекты сопоставительного анализа включают перевод Лу Синем произведений Гоголя на китайский язык, влияние творчества Н.В. Гоголя на творчество Лу Синя, отличия в литературных приемах, специфику образов человека в произведениях

\footnotetext{
${ }^{1}$ Китайская национальная электронная платформа научных продуктов. Включает китайские научные журналы на английском и на китайском языках, диссертации и ежегодники по широкому спектру дисциплин.
} 
этих писателей, художественная идея, цель творчества, сравнительный анализ повестей Записки сумасшедшего и Дневник сумасшедшего (или же Записки сумасшедмего) и т. д.

Эти исследования, с одной стороны, демонстрируют историю развития современной китайской литературы, с другой стороны, показывают изменение и развитие литературоведения в Китае. Изучая имеющиеся работы, можно заметить, что научная парадигма исследований творчества Лу Синя и Н.В. Гоголя в течение 70 лет сильно изменилась от революичинной к литературной. Термины революичонная парадигма (革命范式) 2 и литературная парадигма (文学范式) ${ }^{3}$ переведены с китайского языка из-за их уникальности в китайском литературоведении. Изучение любого предмета, как правило, проходит в рамках определенной парадигмы, а смена парадигм происходит под влиянием многих факторов, включая эстетические, социальные и политические, а также под влиянием зарубежных теорий и подходов.

Цель статьи заключается в изучении 70-ти летней истории сопоставительного анализа творчества Н.В. Гоголя и Лу Синя в контексте развития китайской литературы и литературоведения.

Научная новизна. Данная статья представляет собой попытку систематического изучения истории сопоставительного анализа творчества Н.В. Гоголя и Лу Синя в Китае за последние 70 лет.

Изложение основного материала исследования. Считается, что сопоставительный анализ Н.В. Гоголя и Лу Синя в Китае за последние 70 лет можно разделить на три этапа, изучение творчества этих писателей в 50-70-х годах XX века и после 80-х годов XX века демонстрирует совершенно разные подходы. В 50-70-х годах $\mathrm{XX}$ века китайские ученые высоко оценивали политическую функцию литературы, а после 80-х годов в китайском литературоведении основное внимание начинают уделять эстетической функции.

1. Причины, по которым китайские ученые придают большое значение сопоставительному анализу Гоголя и Лу Синя

Во-первых, влияние русской литературы на развитие современной китайской литературы. В процессе зарождения и развития современной китайской литературы русская литература сыграла важную роль, особенно наглядно проявилось это в период «Движения четвертого мая» 1919 г., когда произведения русской литературы массово переводились на китайский язык. По статистике Антологии современной китайской лите-

\footnotetext{
${ }^{2}$ Китайский ученый Гао Юй изображает такое понятие как «изучение произведения Лу Синя с аспекта политической революции»

Китайский ученый Линь Вэйна использует термин «эстетическая парадигима».
}

pamypы, за период с 1917 nо 1927 г2., в Kumae было издано 200 переводов литературно-художественных изданий, среди которых 65 русских литературных произведений, 31 франиузское, 24 немецких и 21 английское [4]. В процессе перевода литературных произведений переводится и создаётся ряд исследований о русской литературе.

В сентябре 1921 года был издан вкладной лист № 12 Fiction Monthly, в который была включена специальная тема - Изучение русской литера$m y p b l$, и где содержались такие статьи, как: Происхождение русской литературы (Чжэн Чжэньдуо), Биография четырех великих русских писателей (Гэн Цзичжи), Биография 30 современных русских писателей (Шэнь Яньбин), Русская эстетика и искусство (Го Шаоюй), Эпическая поэма в русской литературе (Шэнь Цзэминь), а так же многие статьи Лу Синя, Цюй Цюбо и Гэн Цзичжи. Эти переводческие работы и знакомство с русской литературой соответствовали потребностям в интеллектуальном просвещении на фоне социальной революции в Китае, оказали глубокое влияние на возникновение литературы Движения четвертого мая и современной китайской литературы в целом.

Во-вторых, Лу Синь - один из первых переводил и рекомендовал произведения Гоголя китайским читателям. В 1934 году его перевод с японского гоголевской повести Нос был напечатан в журнале Иностранные литературные произведения: перевод. В 1920 году Лу Синь начал перевод с немецкого языка поэмы Мертвые души (первый том), который публиковался с марта по октябрь 1935 года в сборнике Всемирная библиотека под редакцией Чжэн Чжэндуо. В 1935 году, обнаружив в своем переводе с немецкого языка много неточностей, Лу Синь, несмотря на то, что его состояние здоровья ухудшилось, решил издать перевод с языка оригинала Полного собрания сочинений Гоголя. Из-за смерти Лу Синя в 1936 году этот проект не был осуществлен. В год смерти Лу Синя в журнале Иностранные литературные произведения: перевод вышел перевод поэмы Гоголя Мертвых души (второй том). Позже все эти переводы вошли в Полное собрание сочинений Лу Синя.

В-третьих, произведения Гоголя оказали сильное влияние на творчество Лу Синя. Лу Синь неоднократно заявлял сам, что его повести были созданы «на основании прочитанных сотен иностранных произведений и полученных медицинских знаниях» [12, с. 524], «Я брал пример, в основном, с зарубежной литературы» [12, с. 434]. Он заимствовал идеи и методы у зарубежных писателей, среди которых Гоголь считается «одним из самых любимых». В 1918 году Лу Синь написал рассказ Дневник сумасшедиего, название которого, 
форма дневника, главная идея и призыв в конце «Матушка, спаси твоего бедного сына!» очень схожи с Записками сумасшедшего Гоголя, хотя социальный фон у этих двух произведений разный. Лу Синь в своем рассказе критиковал устаревшую социальную систему и культуру Китая того периода. Дневник сумасшедшего - первый в истории современной китайской литературы рассказ, написанный на языке байху $a^{4}$; его идеи стали обобщением идей современного китайского просвещения, оказали глубокое влияние на развитие литературоведения Китая в XX веке.

2. 20-40 годы XX века: знакомство с творчеством Гоголя в Китае, его распространение и первоначальное изучение

Лу Синь - один из первых китайских ученых, обративших внимание на творчество Гоголя. В 1907 году в статье $O$ силе дьяволизма он писал: «Гоголь был мастером в изображении тьмы общественной жизни» [12, с. 89] и «воодушевлял своих соотечественников невидимыми следами слез и печали» [12, с. 66].

Интерес к творчеству Гоголя активизировался в Китае в 20-е годы XX века. В июле 1920 года Гэн Цзичжи перевел рассказ Коляска из Петербургских повестей, через год Гэн Цзичжи представил в переводе повесть Записки сумасшедшего и издал в журнале Fiction Monthly. В 1926 году в центре внимания переводчиков оказалась повесть Шинель, автором перевода был Вэй Суйюань. В 30-40-х годах XX века немало произведений Гоголя уже было переведено на китайский язык, некоторые из них (глава вторая из поэмы Мертвые души, Записки сумасшедшего, Портрет, Коляска) были включены в Сборник рассказов Гоголя (1934 г, Сяо Хуацин). В 1936 году Мэн Шихуань перевел циклы повестей Вечера на хуторе близ Диканьки и Миргород; в 1948 году Цзян Чуньфан издал комедию Игроки.

В этот период начинается изучение творчества Гоголя. Гэн Цзичжи в статье Биография четырех великих русских писателей признавал Гоголя первым писателем-реалистом в России, и первым в литературе Китая заимствовал высказывание смех сквозв слезы. В 1923 году Чжэн Чжэньдуо опубликовал в Fiction Monthly статью Главная история русской литературы, в которой отмечал, что у произведений Гоголя реалистический стиль. В 1927 году Чжэн Цычуань в труде История современных повестей в Европе и Америке отметил, что «творчество Гоголя является началом реализма в русской повести» [19, с. 45]. В 1935 году в журнале Издание была опубликована статья Мертвые души Гоголя (Чжоу Ян), в

\footnotetext{
${ }^{4}$ Разговорный китайский язык, который начал формироваться в Китае в начале династии Тан (VII-Хвв.). и впоследствии стал основой современного китайского языка
}

которой автор утверждал, что поэма Mepmвые души «внесла выдающийся вклад в формирование критического реализма в России» [20, с. 621], а сатира на бюрократов-чиновников в данном произведении Гоголя показывает «ярмарку пороков» феодального общества России» [20, с. 621].

Лу Синя интересует в произведениях Гоголя забота о реальном обществе и о судьбе маленького человека. В статье Как я начал писать он отмечал: «Меня интересует тема борьбы в литературном произведении, что непременно относится к восточно-европейской литературе, поэтому я много читаю произведений писателей из России, Польши и стран Балканского полуострова...... Помню, что самые любимые писатели, произведения которых мне нравилось читать, - это Гоголь и Сенкевич» [12, с. 525]. В эссеистике Лу Синь неоднократно говорил о Mертвых душах, например, оценивал героев: «Всего описал 5 типичных помещиков, они действительно сатирические, но на самом деле, кроме старухи (Коробочки) и скряги Плюшкина, у всех есть свои прелести. Что касается крепостных крестьян, там нет ничего милого; то, что они искренне приходили на помощь помещикам, не только не приносило никакой пользы, но и наоборот, вредило. Гоголь сам является помещиком» [11, с. 363]. Лу Синь высоко оценивал творчество Гоголя, считал, что знакомство с его произведениями принесет пользу Китаю, поэтому он активно знакомил китайских читателей с творчеством Гоголя.

Лу Синь сам впервые сделал сравнительный анализ своего творчества и творчества Гоголя. В 1935 году в предисловии ко второму тому Антологии современной китайской литературы он сопоставил Записки сумасшедшего и Дневник сумасшедшего: «Русский писатель Гоголь в 1834 году написал Записки сумасшедмего...... Но цель Дневника сумасшедшего Лу Синя - проявить недостатки родового строя и феодальных нравственных норм, поэтому произведение его является более критическим и значительным» [11, с. 241]. Лу Синь оценивает произведение с точки зрения мотивации его творения, что, в сочетании с предыдущими комментариями Лу Синя о Гоголе, приводит к выводу: Лу Синь представлял и переводил произведения Гоголя с четкой целью - «С помощью зарубежных произведений изменить устаревшие обычаи и улучшить общество» [3, с. 2]. Лу Синь придавал большое значение революционности в творчестве Гоголя, надеялся использовать его для пробуждения китайского народа, позволить им отказаться от старых, укоренившихся в их мышлении идей, изучать передовой опыт и культуру других стран мира, способствовать изменениям в обществе и процветанию страны. Под влиянием произведения Дневник сумасшедшего в 
китайской литературе происходит подъём романа на актуальную тематику. Многие работы были посвящены социальной реальности, критике и разоблачению национализма. В этот же период и другие китайские ученые начали изучение творчества Лу Синя и Гоголя. Значительное влияние на более поздних ученых оказали высказывания и оценки самого Лу Синя.

3. 50-70 годы XX века: появление революционной парадигмы

С конца 19 века, особенно после Синьхайской революции 1911 года, в Китае были популярны реформы традиционной культуры. Многие интеллигенты под влиянием западной культуры (включая культуру Японии после реставрации Мэйдзи) выступали за реформы в традиционной литературе и языке Китая, формировали Движение за новую литературу. В то время было переведено на китайский язык и представлено Китаю большое количество иностранных литературных произведений; китайские писатели заимствовали опыт иностранной литературы для создания произведений новых стилей с новыми темами и идеями на литературном языке байхуа, что стало начальным этапом развития современной китайской литературы. В то время русский критический реализм, представленный произведениями Гоголя, был очень популярен в Китае. После основания Китайской Народной Республики под влиянием международных отношений и идеологии левая литература постепенно занимает доминирующие позиции, социалистический реализм, революционный романтизм и революционный реализм стали ведущими направлениями. В целом китайская литература постепенно стала закрытой для мировой литературы, под влиянием теории соцреализма и произведений советской литературы в китайской литературе и науке о ней сформировалась уникальная револючионная парадигма, которая характерна и на этом этапе для сопоставительного анализа творчества Гоголя и Лу Синя.

В 1952 году Фэн Сюэфэн в статье Лу Синь $и$ Гоголь - К столетию со дня смерти Н.В. Гоголя исследовал влияние русского автора на китайского и пришёл к выводу, что Лу Синь подражал Гоголю из-за того, что видел социальную функцию и роль гоголевского произведения в литературе. Фэн Сюэфэн отметил, что поскольку Лу Синь жил в период социальной революции в Китае, «реализм в его произведениях, в свою очередь, естественно, был более прогрессивными и революционными, чем в произведениях Гоголя...» [7].

В контексте революиионной napaduгмы, прогрессивность и социальная функция произведений стали главным предметом интереса китайских ученых, в том числе в области сравнительного литературоведения. В 1957 году Фэн Веньбин указывал: «Когда Лу Синь создавал такое искусство с воспитательным значением, он не взял образ из своего социального класса, как Гоголь, что указывало бы на чрезвычайно глубокие идеологические чувства Лу Синя. Он хотел воспитывать людей своего социального класса, а в результате пробуждал угнетённых и эксплуатируемых маленьких людей и стойко стоял на их стороне» $[6$, с. 53]. Лу Яодун прямо написал: «Гоголь был недоволен только некоторыми темными явлениями в обществе, а Лу Синь хотел ниспровергнуть все старое общество» $[13$, с. 53$]$.

Чрезмерное внимание к значению прогрессивности и социальной функции литературных произведений приводило к игнорированию их эстетической ценности. В 1961 году Хань Чанцзин отмечал: «Несмотря на влияние Гоголя, творческие методы Лу Синя под руководством демократической революции и коммунизма, конечно, намного более зрелы и превосходны, чем Гоголя» [9, с. 36]. В 1963 году он подчеркивал: «У них в повестях Записки сумасшедшего близкие жанры и методы выражения, но степень идейности произведений разная» $[10$, с. 79$]$.

4. Период после 80-х годов XX века: формирование литературной парадигмы

Начиная с 80-х годов XX века, когда культурная революция (1966-1976) в Китае уже завершилась и начала активно внедряться политика реформ и открытости, в том числе в сферах культуры, образования, экономики, науки и техники и др., в литературе, наряду с традиционным реализмом и романтизмом, зарождаются модернизм, постмодернизм и литература в стиле постмодернизма, к которым в китайском литературоведении относят туманную поэзию, посттуманную поэзию, авангардизм, экспериментальный роман, новый исторический роман, новый реалистический роман и т.д. Раскрепощение мышления повлекло за собой свободу творчества, благодаря чему было создано много прекрасных литературных произведений. Данная смена парадигмы нашла свое отражение в серии конференций, посвященных творчеству, литературе и искусству, и проведенных в рамках IV съезда Всекитайской ассоциации работников литературы и искусства. В поздравительной речи на церемонии открытия данного съезда Дэн Сяопин сказал: «В теории искусства нужно поощрять разные точки зрения и свободные дискуссии между разными направлениями» [5, с. 6], и это открыло новый широкий путь для развития литературной критики в Китае.

С 80-х годов XX века появилось много исследований, посвященных вопросам сравнительного анализа творчества Гоголя и Лу Синя, свободных от односторонности и ограниченности, обусловленных револючионной парадигмой. В этот период ученые, с одной стороны, следовали точке 
зрения, что Гоголь сильно повлиял на творчество Лу Синя, с другой стороны, осознавали неточность и односторонность сопоставлений исключительно с позиций диктуемых революционной парадигмой подходов и методов. Шао Бочжоу в статье Три вопроса о Записках сумасшедшего рассматривал жанр, образ главного героя, степень идейности и творческий метод двух одноименных повестей, и пришел к выводу, что Дневник сумасшедмего Лу Синя не подражание, а результат творческого переосмысления: во-первых, безумец у Гоголя является настоящим умалишенным, а у Лу Синя - символическим образом; во-вторых, Гоголь - реалист, а Лу Синь близок к символизму. Существенную роль в интерпретации среды, обстоятельств и персонажа сопоставляемых произведений сыграли время, пространство и социальные условия. Гоголь творил Записки сумасшедшего в феодально-крепостнической Российской империи после поражения восстания декабристов, а в период творческой деятельности Лу Синя феодальная монархия в Китае была уже свергнута и общество срочно нуждалось в раскрепощении мышления. Именно поэтому, по сравнению с Лу Синем, «мышление у Гоголя не достигло высоты революционной демократии» [16, с. 24].

В то же время внимание китайских ученых привлекло развитие литературоведческих исследований за рубежом. В 1981 году Шень Юй перевел статью чешского исследователя Ярослава Прусека Былое Лу Синя: предвестник китайской современной литературы.

Из-за взрыва исследований произведений Лу Синя и Гоголя в конце 80 -х годов начали упорядочивать и систематизировать историю сопоставительного анализа Лу Синя и Гоголя, чему посвящена, например, статья Краткое изложение сопоставительного анализа Лу Синя с русской и советской литературой (Ли Чуньлинь).

С 90-х годов ХХ века в результате освобождения от ограниченности революционной парадигмы и развития новых литературных теорий в сопоставительном анализе творчества Лу Синя и Гоголя проявляется тенденция к диверсификации. Основное внимание уделяется литературным характерам, поэтическим достоинствам произведений, литературная парадигма постепенно заменяла революиионную парадигму. Например, Ван Чжигэн фокусируется на влиянии эстетических принципов творчества Гоголя на современную китайскую литературу, представленную Лу Синем. Исследователь полагает, что эстетический принцип Гоголя - смех сквозь слезы - оказал влияние на развивающуюся в китайской литературе сатиру благодаря тому, что был введен в литературный дискурс благодаря переводам Лу Синя, который и сам был приверженцем такого подхода к изображению действительности, например, в произведениях Кун И-изи, Подлинная история

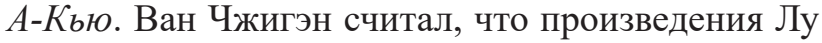
Синя наполнены атмосферой, близкой гоголевскому «смеху сквозь слёзы» [17, с. 45].

В статье Психическая реальность, стоящая за образами Яо Итин проанализировала художественный мир произведений двух авторов с одинаковым названием (Записки сумастедшего) и установила, что луна у Гоголя недостижимая, как поэтическое жсилище человечества, а появление лунного света в творчестве Лу Синя означает «пробуждение разума и совести в глубине души безумца» [18, с. 15]. Кроме того, образ собаки у Лу Синя также проявляет значение «поедать людей». Автор считает, что, заимствуя эти образы, Лу Синь локализовал их. Сунь Юй рассматривал перевод и понимание творчества Гоголя Лу Синем как типичный пример, того, что «выражает психическое состояние и ценностные ориентации у современных китайских писателей при изучении зарубежной литературы. Критическое сознание и эстетическая эволюция в китайской литературе тесно связанны с добровольным принятием иностранной литературы писателями Китая» [15, с. 13]. Лу Синь не догматически наследовал Гоголя, а творил «на основании родовой традиции и культуры» $[15$, c. 13$]$.

Ли Аньци в статье История изучения повести «Записки сумасшедшего» Лу Синя в Китае в контексте влияния одноимённого произведения H.B. Гоголя рассматривается преемственность и различия во взглядах китайских учёных в разные периоды (с 1919 г. и до сегодняшнего дня) в отношении вопроса связи между двумя указанными одноимёнными произведениями в Китае. В этой статье автор также отметила, что, по мнению китайских ученых, у Лу Синя существуют заимствования из Гоголя «на уровне формы (оба произведения написаны в жанре дневника, повествование ведётся от первого лица; такого опыта не было в китайской литературе до повести Лу Синя), на стилевом уровне (большинство исследователей признают доминирующим направлением двух произведений реализм, хотя ряд ученых отмечает в двух повестях черты таких стилей, как романтизм и символизм)» [1, с. 32].

Чжоу Сяовэй в статье Исследование творчества Н.В. Гоголя в Китае проанализировал творчество Н.В. Гоголя в контексте межкультурной коммуникации. Автор отметил, что «ироническая манера Лу Синь в значительной степени усвоена из стиля Гоголя. Главными особенностями творчества Лу Синя, унаследованными от Гоголя, являются следующие две черты: - ирония над бытовыми явлениями; - ирония с намёком. Обе особенности связаны с крылатыми выражениями Гоголя» [2, с. 145]. 
Выводы. Сопоставительный анализ творчества Лу Синя и Гоголя давно стал предметом исследования китайских ученых. В начале $\mathrm{XX}$ века русская литература массово переводилась на китайский и глубоко влияла на развитие современной китайской литературы. Как один из первых переводчиков Лу Синь не просто сделал большой вклад в перевод и распространение произведений Гоголя в Китае, но и создал под влиянием русского классика ряд произведений, ставших классикой современной китайской литературы.

В разные периоды развития современной китайской литературы и литературоведения проявлялось разное отношение к литературе, творчеству конкретных авторов, и вопросам литературного процесса. До создания Китайской Народной Республики изучение Гоголя в Китае оставалось на первичном этапе, в 50-70-х годах XX века имело место изучение характера творческих связей Лу Синя и Гоголя в рамках револющионной napaduгмbl, с 80-х годов по сегодняшний день сформировалась и стала доминирующей литературная парадигма.

Рассмотрение истории сопоставительного анализа творчества Лу Синя и Гоголя позволяет сделать следующие выводы:

1. Социальная среда и потребность в реформе мышления в разные периоды развития Китая сильно влияет на фокус исследований ученых. Лу Синь занимает важное место в развитии левой литературы Китая. Мао Цзэдун в свое время отметил, что произведения Лу Синя идеологически выдержаны, поэтому китайские исследователи стали уделять больше внимания роли этих произведений в обществе и их идеологической направленности, чем эстетической ценно- сти. В течение долгого времени после основания Китайской Народной Республики исследования творчества Лу Синя в целом велись с точки зрения его социально-исторической ценности, что невольно акцентировало внимание на революиионном характере его произведений и превращало их в эталон измерения прогрессивности для произведений других авторов, пренебрегая при этом их эстетическими аспектами и постепенно отклоняясь от самой литературы.

2. Револючионная парадигма в изучении литературных произведений является продуктом национального кризиса и непрерывных социальных волнений, с которыми Китай столкнулся после Опиумной войны 1840 года. В рамках революционной парадигмы как одной из литературных теорий обращается внимание на прогрессивность в ходе истории и социальную функцию творчества, литературные произведения рассматриваются как инструмент пробуждения народа и содействия социальному прогрессу, а многие классические китайские и зарубежные литературные произведения, которые не соответствуют такому требованию, девальвируются и подвергаются критике, литературное творчество при этом становится более однообразным.

3. Появление переводов произведений западной литературной критики в Китае стимулирует развитие китайского литературоведения. По словам Гао Юй, «каждый прорыв в изучении современной китайской литературы связан либо с самостоятельным развитием литературоведения в Китае, либо с внедрением западных литературных теорий там» [8, с. 176]. В результате таких процессов научная парадигма в изучении творчества Лу Синя и Гоголя изменилась от револющионной к литературной.

\section{ЛИТЕРАТУРА}

1. Ли Аньци. История изучения повести «Записки сумасшедшего» Лу Синя в Китае в контексте влияния одноимённого произведения Н.В. Гоголя. Litera. 2019. № 4. С. 26-34.

2. Чжоу Сяовэй. Ислледование творчества Н.В. Гоголя в Китае. Гуманитарный вектор. Сер. Философия. Культурология. 2016. Т. 11, № 2. С. 143-147.

3. 曹靖华. 从“五四”初期的外国文学介绍谈起. 世界文学. 1959. Вып. 4. С. 2-6.

4. 陈国恩. 论俄苏文学对20世纪中国文学的影响. 外国文学研究. 2004. Вып. 2. C. 97-103.

5. 邓小平. 在中国文学艺术工作者第四次代表大会上的祝词 (一九七九年十月三十日). 文艺理论与批 评. 1997. C. 4-9.

6. 冯文炳. 阿Q正传. 东北人民大学人文科学学报. 1957. Bып. Z1. C. 43-79.

7. 冯雪峰. 鲁迅和果戈里一为果戈里逝世百年纪念而作. 人民日报. 1952.03.04.

8. 高玉. 文学理论与中国现当代文学研究. 社会科学. 2020. Вып. 2. C. 171-181.

9. 韩长经. 鲁迅论俄国批判的现实主义文学. 文史哲. 1961. Вып. 2. C. 33-40.

10. 韩长经. 鲁迅早期思想所受俄国古典文学的影响.山东大学学报(语言文学版)。 1963. Вып. S7. C. $68-80$.

11. 鲁迅. 鲁迅全集. 人民文学出版社. 北京. 1973.

12. 鲁迅. 鲁迅全集. 人民文学出版社. 北京. 2005.

13. 陆耀东. 论《呐喊》《彷得》的几个艺术特色. 武汉大学学报(人文科学). 1962. Вып. 2. C. 50-63.

14. 普鲁塞克.雅罗斯拉夫, 沈于. 鲁迅的《怀旧》. 中国现代文学的先声. 文学评论. 1981. Вып. 5. C. 66-69. 
15. 孙郁. 鲁迅与果戈理遗产的几个问题. 文学评论. 2013. Вып. 3. C. 5-14.

16. 邵伯周. 《狂人日记》研究三题.上海师范大学学报(哲学社会科学版). 1983. Вып. 2. C. 16-24.

17. 王志耕. 果戈理的审美原则与中国新文学.上海大学学报(社会科学版). 1990. Вып. 6. C. 42-48.

18. 姚怡婷, 意象背后的心理真实, 文学评论, 2011. C. 15.

19. 郑次川. 欧美近代小说史. 上海. 商务印书馆. 1927. C. 45.

20. 周扬. 果戈理的死灵魂. 文学. 1935. C. 621 .

\section{REFERENCES}

1. Li Anqi. Istoriya izucheniya povesti zapiski sumasshedshego lu sinya $\mathrm{v}$ kitae $\mathrm{v}$ kontekste vliyaniya odnoimyonnogo proizvedeniya $\mathrm{n} v$ gogolya [Analysis of Chinese studies of Lu Xun's novel 'Notes of the madman' in terms of the influence of Nokolal Gogol’s same-named novel]. Litera. 2019. № 4. C. 26-34.

2. Zhou Xiaowei. Issledovanie tvorchestva $n v$ gogolya $v$ kitae [Research of N. V. Gogol's Works in China ]. Humanitarian Vector. Series Philosophy. Cultural Studies. 2016. Vol. 11, No 2. P. 143-147.

3. Cai Jinghua. Cong "Wusi" Chuqi de Waiguowenxuejieshao Tanqi[From the Foreign Literature Introduction in preliminary stage of "May Fourth Movement" ]. World Literature. 1959. Vol. 4. P. 2-6. [in Chinese]

4. Chen Guoen. Lun Su'ewenxue dui 20 Shiji Zhongguowenxue de Yingxaing [the Russian Soviet Literature Influence on modern Chinese Literature in the 20th Century]. Foreign Literature Studies. 2004. Vol. 2. P. 97-103. [in Chinese]

5. Deng Xiaoping. Zai Zhongguo Wenxueyishu Gongzuozhe Disici Daibiaodahuishang de Zhuci [Speech greeting the Fourth Congress of Chinese writers and artists]. Theory and Criticism of Literatureand Art . 1997. P. 4-9. [in Chinese]

6. Feng Wenbing. A QZhengzhuan [The True Story of Ah Q ]. Northeast People's University Journal Social Sciences Edition. 1957. Vol. Z1. P. 43-79. [in Chinese]

7. Feng Xuefeng. Guogeli he Lu Xun——Wei Guogeli Shishibainian Ji'nian erzuo [Gogol and Lu XunFor the Death centenary of N. V. Gogol]. People's Daily. 1952.03.04 [in Chinese]

8. Gao Yu. Wenxuelilun yu Zhongguo Xiandangdai Wenxueyanjiu [Literary Theory and Chinese Modern Literature Research]. Journal of Social Sciences. 2020. Vol. 2. P. 171-181. [in Chinese]

9. Han Changjing. Lu Xun lun E'guo Pipande Xianshizhuyi Wenxue [Lu Xun's Comment on Russian Critical Realism Literature]. Journal of Literature, History \& Philosophy. 1961. Vol. 2. P. 33-40. [in Chinese]

10. Han Changjing. Lu Xun Zaoqisixiang Suoshou E'guogudianwenxue de Yingxiang [The Influence of Russian Classical Literature on Lu Xun's Early Thoughts]. Journal of Shandong University (Philosophy and Social Sciences). 1963. Vol. S7. P. 68-80. [in Chinese]

11. Lu Xun. Lu Xunquanji [Complete Works of Lu Xun]. People's Literature Publishing House. Beijing. 1973. [in Chinese]

12. Lu Xun. Lu Xunquanji [Complete Works of Lu Xun]. People's Literature Publishing House. Beijing. 2005. [in Chinese]

13. Lu Yaodong. Lun Nahan, Panghuang de Jige Yishutese[Many artistic skills of "Call To Arms" and "Pang Huang"]. Wuhan University Journal (Arts Humanity). 1962. Vol. 2. P. 50-63. [in Chinese]

14. Pulusaike Yaluosilafu, Shen Yu. Lu Xun de "Huaijiu": Zhonguo Xiandaiwenxue de Xiansheng [Lu Xun's "Huaijiu": Harbinger of Chinese Modern Literature]. Literary Review. 1981. Vol. 5. P. 66-69. [in Chinese]

15. Sun Yu. Lu Xunyu Guogeli Yichande Jigewenti[Lu Xun and Many questions about Gogol's literature]. Literary Review. 2013. Vol. 3. P. 5-14. [in Chinese]

16. Shao Bozhou. Kuangrenriji Yanjiusanti [A Madman's Diary: three questions]. Journal of Shanghai Normal University(Philosophy Social Sciences Edition). 1983. Vol. 2. P. 16-24. [in Chinese]

17. Wang Zhigeng. Guogeli de Shenmeiyuanze yu Zhongguo Xinwenxue [Gogol's Aesthetic Principles and Chinese Modern Literature]. Journal of Shanghai University(Social Sciences Edition). 1990. Vol. 6. P. 42-48. [in Chinese]

18. Yao Yiting. Yixinag Beihoude Xinlizhenshi[Psychic reality behind toposes]. Literary Review. 2011. C. 15. [in Chinese]

19. Zheng Cichuan. Oumei JindaiXiaoshuoshi [The history of Modern fiction in Europe and America]. Commercial Press. Shanghai. 1927. P. 45. [in Chinese]

20. Zhou Yang. Guogeli de Sihunling [Dead Souls of Gogol]. Literature. 1935. P. 621. [in Chinese] 